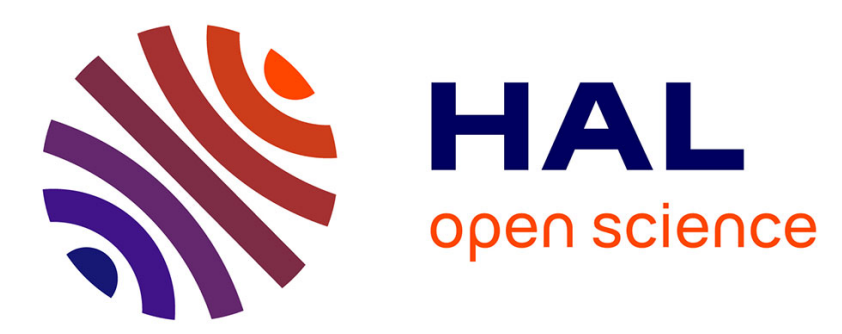

\title{
Do stormwater source control policies deliver the right hydrologic outcomes?
}

\author{
Guido Petrucci, E. Rioust, José-Frédéric Deroubaix, Bruno Tassin
}

\section{To cite this version:}

Guido Petrucci, E. Rioust, José-Frédéric Deroubaix, Bruno Tassin. Do stormwater source control policies deliver the right hydrologic outcomes?. Journal of Hydrology, 2013, 485, pp.188-200. 10.1016/j.jhydrol.2012.06.018 . hal-00809398

\section{HAL Id: hal-00809398 \\ https://hal-enpc.archives-ouvertes.fr/hal-00809398}

Submitted on 6 May 2018

HAL is a multi-disciplinary open access archive for the deposit and dissemination of scientific research documents, whether they are published or not. The documents may come from teaching and research institutions in France or abroad, or from public or private research centers.
L'archive ouverte pluridisciplinaire HAL, est destinée au dépôt et à la diffusion de documents scientifiques de niveau recherche, publiés ou non, émanant des établissements d'enseignement et de recherche français ou étrangers, des laboratoires publics ou privés. 


\title{
Do stormwater source control policies deliver the right hydrologic outcomes?
}

\author{
Guido Petrucci, Emilie Rioust, José-Frédéric Deroubaix, Bruno Tassin
}

\section{Introduction}

In the last five decades, stormwater Source Control (SC) has gained relevance over traditional sewer approaches, mainly for its potential to cope with fast urbanization and non-point source pollution (Bergue and Ruperd, 1994; Delleur, 2003; Urbonas and Jones, 2001). The principle of SC is to develop, simultaneously to urban growth, facilities to manage stormwater at a small-scale (about $10^{2}-10^{3} \mathrm{~m}^{2}$ ) to solve or prevent catchment-scale $10^{6}-$ $10^{7} \mathrm{~m}^{2}$ stormwater problems. These parcel-scale facilities are usually called Best Management Practices (BMPs) in the USA, Sustainable Urban Drainage Systems (SUDSs) in the UK, techniques alternatives in France. Terms like Low Impacts Development (LID) in the USA or Water Sensitive Urban Design (WSUD) in Australia are used today to identify the application of this principle to the whole design of new urban developments, which is typical of an intermediate scale 104-10 $\mathrm{m}^{2}$ (Morison and Brown, 2011; Revitt et al., 2008; Roy et al., 2008; Williams and Wise, 2006). In this paper, we will use "BMP" to address individual stormwater facilities, and "SC" when speaking of the catchment scale strategy.

In a first development phase, SC was realized, in most cases, by large reservoirs built to prevent sewer overflows. Then, the principle of diffused small facilities started to be applied, and a pioneering phase of SC policies began (Chouli, 2006). The first regulations enforceable for all new developments date back to the 1980s: the city of Bordeaux, in France (Bourgogne, 2010) started implementing SC policies in 1982, while the State of Maryland, in the USA, in 1984 (Comstock and Wallis, 2003).

Even if no official inventories of local SC policies are available, in several countries (e.g. France, USA, UK, Brazil) their diffusion strongly accelerated in the last ten years (Ellis et al., 2010). In the USA, EPA regulation urges local authorities to adopt policies (EPA, 2010), and a similar effect is expected, in France, for the SDAGE Seine-Normandie (a large-scale catchment management plan, Section 3.4 of this paper). This change of pace is due to a convergence of technical and political rationalities: SC offers an efficient opportunity for urban stormwater drainage and, in the last years, it acquired an halo of sustainable development that increased SC policies appeal for many local authorities (Novotny` and Brown, 2007).

Because of the accelerated diffusion of regulations demanding widespread construction of BMPs, we can expect in the near future that the hydrologic behavior of many urban and periurban catchments will be influenced, if not determined, by SC. In most cases, this effect will be driven by the policies that are discussed and implemented today. In France, the Seine-Saint-Denis county (Section 3.2), up to 2009, has prescribed 470,000 $\mathrm{m}^{3}$ of BMPs on a territory of $236 \mathrm{~km}^{2}$. Considering an approximate impervious cover of $20 \%$, this represents about $10 \mathrm{~mm}$ of storage on the whole impervious area of the county: a value comparable, for example, to weekly mean evaporation.

In view of this relevance, since the 1960s researchers investigate BMPs performances and efficiency. This effort had practical effects, diffusing good design and construction practices. Several BMPs' selection and design manuals have been published (e.g. Azzout et al., 1994; Bergue and Ruperd, 1994; Clar et al., 2004; Debo and Reese, 2002; Woods-Ballard et al., 2007), that contributed to the actual diffusion of BMPs. However, studies on the global effect of BMPs on a catchment hydrology are still scarce, and so are directions on how to define a 
suitable policy (Roesner et al., 2001; Roy et al., 2008). The transition from a pioneering phase to a rapid and wide diffusion of SC policies makes these questions a priority. If, in the past, efficient design of individual BMPs was the main concern, today it is important to investigate what an effective SC policy at the catchment's scale is.

The hydrological analysis of global effects of SC faces two main difficulties. The first one is that policies effects emerge slowly, at the rhythm of urban growth and renovation. Hence, catchment-wide measurements are still scarce and incomplete (see, for an example, Meierdiercks et al., 2010). Even when data are available, it is difficult to distinguish gradual SC effects from catchment uncontrolled evolutions (Petrucci et al., 2012) or other stormwater management actions, like sewer system developments. The second difficulty concerns spatial scales: passing from parcel-scale BMPs to catchment-scale effects demands a good knowledge of scale-transition processes in urban and peri-urban settings (Cantone and Schmidt, 2009; Chocat and Cabane, 1999). A similar issue has been pointed out for rural small scale surface runoff control measures (O’Connell et al., 2007).

In the absence of comprehensive measurements on catchment-scale effects of SC, researches about this topic have been mainly based on hydrological modeling. Because the purpose of this modeling effort was to extrapolate smallscale known processes (i.e. the behavior of individual BMPs) to predict large-scale unknown effects, most researchers adopted a bottom-up scaling approach (Blöschl and Sivapalan, 1995). In practice, researches on this topic relies mostly on physically-based distributed models (e.g. SWMM, HEC-HMS, MOUSE), allowing for a detailed description of both the BMPs and the large-scale processes. These researches, exploring both water quality (e.g. Freni et al., 2010; Wu et al., 2006) and water quantity effects (e.g. Carter and Jackson, 2007; Emerson et al., 2005; Faulkner, 1999; Goff and Gentry, 2006,: McCuen, 1979; Mouy et al., 2007; Urbonas and Glidden, 1983; Zimmer et al., 2007), allowed to identify some important discrepancy between hydrological studies and actual SC policies (e.g. Booth and Jackson, 1997; Goff and Gentry, 2006; McCuen, 1979).

This paper focuses on these discrepancies: the question is how the policy-making process comprehend - or not hydrological considerations. In order to answer, this paper integrates two complementary approaches to study SC regulations: at first, it presents a regulations' analysis that aims to make explicit the logics behind SC policymaking; then, it discusses these logics through an hydrological analysis of the catchment-scale effects of SC regulations. Section 2 presents a review of researches on water-quantity catchment-scale effects of SC, focusing on the discrepancies between SC policies and hydrological outcomes. The regulations' analysis is presented in Section 3: three case-studies of SC policy-making are discussed to find how, and on which logics, regulations are developed today. Section 4, through the physically-based distributed model of a peri-urban catchment, assesses consequences, at the catchment-scale, of widely applied regulations. Sections 3 and 4 are based on French cases, but both the methodology and several results could be extended to other countries where SC is developing.

\section{Background and research approach}

Despite the difficulties highlighted in the introduction, hydrological analysis of global effects of SC provided some general guidance on how to design policies. For example, as BMPs must be adapted to their specific site, SC policies should be conceived according to the specific catchment's characteristics (Ellis et al., 2007; EPA, 2010). Another example is that many researchers, starting with the early analysis of McCuen, 1979, agree on the fact that hydrographs timing must be taken into account when planning storage facilities: a local reduction of hydrographs' peak flow can produce a catchment-scale increase due to peaks' superposition (Fig. 1). 


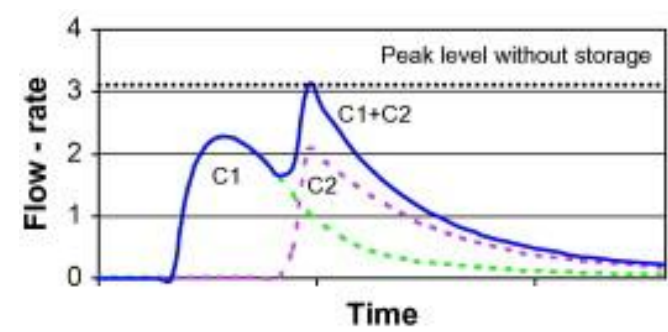

Hydrographs'

superposition

without storage

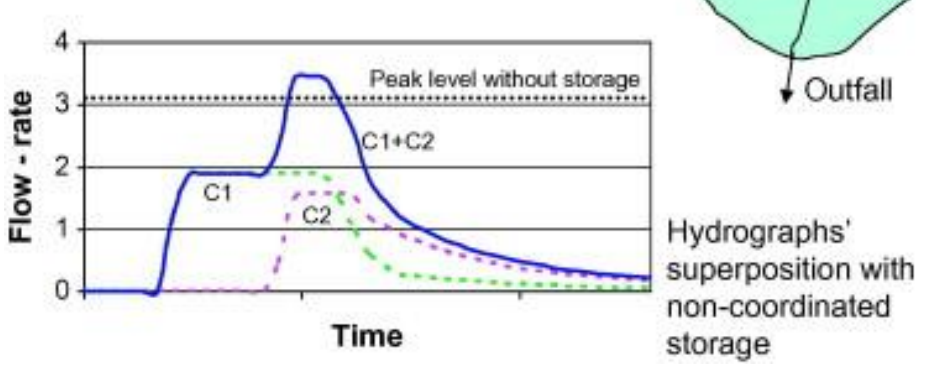

Fig. 1. Peaks' superposition due to storage facilities (adapted from Azzout et al., 1994).

It is surprising that, even if these general ideas gather relevant consensus among scientists, many implemented policies are in contrast with them. Many French policies impose a unique value — often very low—of admitted flow-rate from parcels (i.e. in the form of a $x \mathrm{~s} \mathrm{~s}^{-1} \mathrm{ha}^{-1}$ constraint) over entire regions, without considering catchments' specificities or hydrographs' superposition. Some UK regulation shows the same shortcomings (Faulkner, 1999). In the USA, regulations often demand to preserve pre-development peak flow-rates downstream of parcels (Balascio and Lucas, 2009; Fennessey et al., 2001), ignoring peaks' superposition effects (Emerson et al., 2005).

A complementary remark about current policies is that, even if they often involve different instruments to develop SC (e.g. recommendations to infiltrate or reuse stormwater, financial or technical support), most of them fix a regulation on maximum flow-rate downstream of parcels as the only quantified constraint. Today, many scientific works converge in criticizing this kind of flow-rate regulations.

The first critic is that SC policies explicitly or implicitly aim, in general, to preserve pre-development water balance: it has been shown that flow-rate constraints are, in most cases, unable to achieve this goal. In particular, these constraints do not cope with reduced infiltration volumes due to imperviousness, and distort downstream low-flow regimes (Booth and Jackson, 1997; Fennessey et al., 2001). Meierdiercks et al., 2010 analyzed ten years of runoff data to compare three catchments: one undeveloped and two developed, respectively, before and after the adoption of a SC regulation (flow-rate based). In terms of hydrologic behavior, the catchment developed with $\mathrm{SC}$ is closer to the one without SC than to the one undeveloped.

The second critic is about peak flow-rate: as stated above, provisions demanding to preserve pre-development peak flow-rate locally, can actually worsen the situation at the catchment-scale (Emerson et al., 2005; Goff and Gentry, 2006; McCuen, 1979), depending on catchment's timing characteristics. Regulations demanding a specific value of flow-rate can have adverse effects on peak flow-rate until the catchment is not completely urbanized, because superpositions between regulated and non-regulated flows can occur. This last type of regulation can also affect intermediary flows, responsible of combined sewer overflows (CSOs). A study of the city of Paris (Mouy et al., 2007) showed that limiting flow-rates could be effective in reducing peak flow-rate and sewer overflows, but could 
increase frequency and duration of CSOs. Booth and Jackson (1997) proposed, in order to avoid these problems, to base regulations on runoff characteristics different from flow-rates; Emerson et al. (2005), more specifically, suggested limiting runoff volumes.

In contrast with the traditional regulations quantifying flow-rates, some authority is adopting policies that prescribe a volume that must be treated at the parcel-scale, without sending it to the sewer network. In the city of Paris, redevelopments have to integrate an infiltration area capable to collect, store and infiltrate a volume of rainwater corresponding to 4-12 mm (Mouy et al., 2007). In the absence of infiltration possibilities green roofs can be used. In the USA, Bollig (2007) reports of a urban runoff mitigation ordinance in Sun City, Arizona, requiring a reduction in runoff corresponding to $0.75^{\prime \prime}(19 \mathrm{~mm})$. On a larger scale, the 2000 Maryland Stormwater Design Manual prescribes that stormwater ponds must retain volumes for water quality and groundwater recharge (Comstock and Wallis, 2003).

In general, the effect of SC on a catchment will depend on both the characteristics of the catchment (topography, geology, climate, urban development) and of the regulation (type, level of constraint). Most of the studies focus on catchments' variability, while regulations' variability is seldom considered in depth, despite its relevance for policy-making (among the cited studies, only Fennessey et al. (2001) and Mouy et al. (2007) compare several regulations). Studies on catchments' variability support the idea that flow-rate regulations can be ineffective and even harmful for some catchments, but they do not help defining which values of the limit can be effective, ineffective or harmful. Similarly, there are evidences that runoff volume regulations can be effective for peak flowrate reduction at the catchment-scale, but we do not know the link between constraint level and effectiveness.

To analyze the effect of regulations' variability on a periurban catchment, one option is to consider the "transient state", where the catchment is only partially equipped with BMPs, or the "steady state", where all the urban areas are equipped. In the first case, the focus can be on peaks' superpositions between controlled and uncontrolled areas. In the second case, regulation's effect does not depend on spatial distribution of BMPs in the urban area, but on the regulation type and on the level of constraint. In Section 4 of this paper, the "steady state" approach is applied to the study of a periurban catchment in the Paris region, representative of the drainage conditions of the regional 1950-2000 urbanization. The model of this catchment is used to perform a set of simulations of flow-rate and volume regulations, with varying constraint values.

Because of the dependence on catchment's characteristics, generalization of results obtained on a single catchment should be done carefully. Nevertheless, the analysis of a specific case-study can provide information about the possible behavior (or type of behavior) that a catchment can have when submitted to SC, and thus orient subsequent research and policy-making efforts. In particular, it can help to identify potentially harmful shortcomings in policymaking.

\section{Regulations' analysis}

\subsection{Methodology}

To analyze logics behind SC policies, we present three French case-studies representative of several spatial scales and degrees of urbanization (Fig. 2). For each case, we conduct a survey based on official documents, technical presentations and semi-structured interviews (Quivy and Van Campenhoudt, 1995) of technical staff. The purpose 
of the surveys was to reconstruct the historical process of SC policy-making. We focused on the policies' objectives, the relations to territorial characteristics and the technical framing. The various written sources were collected in order to construct, for each case, an initial "factual framework" of SC policy evolution. The interviews, cross-checked and compared with the available data, were treated like witnesses' accounts: they allowed to fill the factual frameworks with the arguments and motivations that driven SC evolution. Following this historical reconstruction, we analyzed the arguments retrieved from an hydrological point of view.

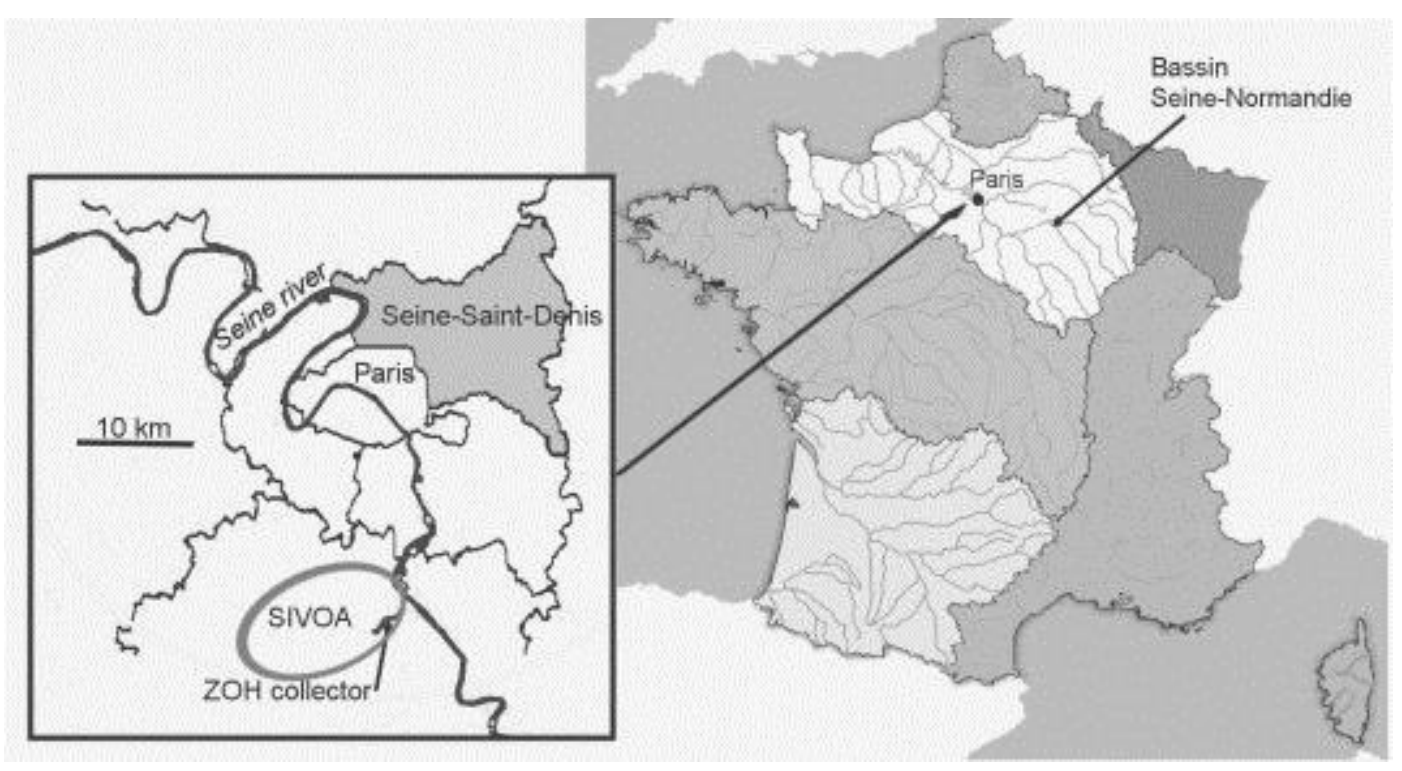

Fig. 2. Geographical position of the three case-studies.

In Sections 3.2, 3.3 and 3.4, we resume the local histories of SC policies for the three cases selected:

1.

the SC strategy of the Seine-Saint-Denis county. This county covers a densely urbanized area $\left(236 \mathrm{~km}^{2}, 1500,000\right.$ inhabitants). It is considered one of the most advanced local authorities in terms of stormwater management in France and an example of a "pioneer" local authority in SC development. For this case, four county's technicians have been interviewed between 2008 and 2010.

2.

The SC strategy of the Syndicat Mixte de la Vallée de l'Orge Aval (SIVOA), an authority in charge of stormwater management in the catchment of the Orge river in the Paris region. This catchment is still mostly rural, but facing a growing urbanization $\left(207 \mathrm{~km}^{2}, 370,000\right.$ inhabitants). The SIVOA applies a SC regulation since the 1990s. Two SIVOA technicians have been interviewed in 2009 and 2010.

3.

The Schéma Directeur d'Aménagement et de Gestion des Eaux Seine-Normandie 2010-2015 (SDAGE), is the River Basin Management Plan for the Seine river and some other small coastal catchments (globally 100,000 km², 18,000,000 inhabitants). This plan (Comité de Bassin Seine-Normandie, 2009) includes SC regulations at a large catchment scale. About this plan, two technicians have been interviewed (2010): one of the catchment authority, and one of the navigation authority for the Seine river, having police power for water discharges in the river. 
These cases are representative of many French current regulations. Moreover, in the discussion we will find that several observations on these cases can be extended, or at least adapted, to SC regulations in other countries.

\subsection{The SC strategy of the Seine-Saint-Denis county}

The territory of the Seine-Saint-Denis county incurred severe stormwater flooding starting from the 1960s. Today, 25 municipalities out of 40 are classed as "strongly" or "quite strongly" exposed to stormwater flooding risk (Préfecture de Seine-Saint-Denis, 2008).

The reasons of this risk exposure are the county's territory configuration (the county is, topographically, extremely flat, with off-centered stormwater natural outfalls) and fast urbanization. Since the 1960s, the county developed a set of strategies to prevent stormwater flooding.

The first strategy adopted was to improve and optimize the sewer network, both building large reservoirs to regulate inflows to the sewer, and developing real-time control of the system. Despite this strategy displayed consistent successes, it also showed its limits: fast urbanization continued, further aggravating flooding risk. County's resources were not sufficient to solve existing flooding problems and, in the same time, to compensate this aggravation.

This situation drove to adopt SC: the county began to demand developers to contribute to stormwater management, building ponds. Dimensioning was based on a $101 \mathrm{~s}^{-1} \mathrm{ha}^{-1}$ flow-rate value. In 2009, the estimated (i.e. prescribed, not verified on the ground) volume of BMPs on the county was about $470,000 \mathrm{~m}^{3}$.

Since 2000, the county undertook two main actions to coordinate municipalities developing local SC strategies: the drawing of a sewer capacity map and of an infiltration map of the county.

The sewer capacity zoning was justified by enduring flood risk in some areas: the sewer was not able to receive $101 \mathrm{~s}^{-1} \mathrm{ha}^{-1}$ everywhere. Thus, the county's technicians identified the critical sections of the sewer and, through a hydraulic model of the sewer system, found the maximal flow capacity in these sections. Upstream area was not considered in the identification of the critical sections, but used for tracing back maximal capacities to an areal flow-rate (i.e. $x \mathrm{l} \mathrm{s}^{-1} \mathrm{ha}^{-1}$ ): the ratio between the capacity in a section and the total catchment area upstream of the section was calculated.

The infiltration map was motivated by pollution concerns: even if limiting flow-rate reduced urban flooding, it was not able to reduce CSO to the Seine river. Thus, it was important to reduce runoff volumes infiltrating stormwater wherever this was possible. An analysis of the pedology of the county has been performed, defining soil permeability and other constraints (e.g. presence of clay or gypsum).

We can remark, in this short history of SC in Seine-Saint-Denis, a trend that is common to most French "pioneer" authorities: SC starts as a reaction to urban flooding, simultaneously to a strategy based on large reservoirs to optimize sewer management. Only later (since the end of the 1980s) SC begins to include water quality as a new objective, that still remains secondary. This evolution has consequences on the actual policies: the $x \mathrm{l} \mathrm{s}^{-1} \mathrm{ha}^{-1}$ form is considered the norm because defining an output flow-rate (and a design rainfall) is the simplest way to define a reservoir that should limit the peak flow-rate in the downstream sewer. 
A difference between reservoirs and BMPs is about infiltration. Reservoirs drain large urban areas and thus the water entering them is, in general, polluted or exposed to high pollution's risks. For this reason, in order to protect the underlying groundwater, infiltration is often proscribed (Bergue and Ruperd, 1994). For reservoirs where infiltration is admitted, it is considered less reliable than storage, because of its natural variability. On the contrary, BMPs drain small areas, with smaller water volumes to be infiltrated and smaller risks of pollution. Thus, infiltration is a main strength of BMPs.

The persistence of reservoir dimensioning practices in SC strategies is evident in the preeminence of the flow-rate approach over infiltration prescriptions. This fact emerges in the duality of the mapping effort of the Seine-SaintDenis county: volume control through infiltration (or water harvesting and reuse) is not seen as an opportunity to limit peak flow-rates in the sewer, but just to protect water quality. Further, while flow-rate is quantified, the main concern about infiltration is only to define if it is possible or impossible.

\subsection{The SC strategy of the Syndicat Mixte de la Vallée de l'Orge Aval}

The SIVOA territory is crossed by the Orge river, a tributary of the Seine. Consequently, storm sewers are mainly structured as parallel linear collectors draining water from municipal networks to the Orge river. In some cases, small tributaries of the Orge are used as collectors and some have been buried under urban areas.

The urban growth of the last fifty years proceeded from downstream areas, close to the river or its tributaries, toward upstream areas. This dynamic is common of many periurban areas in France and other Countries, and it is responsible for a progressive lengthening and saturation of stormwater collectors (Bergue and Ruperd, 1994). Straightened and buried creeks are a common feature of many urban areas, and are often subject to sewer overflows. In the SIVOA only a few areas are prone to this problem, but many collectors (like in the catchment described in Section 4.1.1) are close to saturation while urbanization of their catchments is still going on.

Then, differently from the Seine-Saint-Denis, where earlier flooding problems were frequent, SC policies of the SIVOA are more linked to severe and episodic floods of the Orge river, in particular those of 1978 and 1999 (Fromon and Zuindeau, 1999). In 1992, a study compared available capacity of the Orge river sections with expected urban growth. The result was that the ratio between available capacity at the most critic section and the projected impervious area was $21 \mathrm{~s}^{-1} \mathrm{ha}^{-1}$. The conclusion of the study was to set a precautionary limit of $1 \mathrm{~s} \mathrm{~s}^{-1} \mathrm{ha}^{-1}$ that would be applied in the form of stormwater ponds. Note that, differently from Seine-Saint-Denis, that used for calculations the total upstream area of a critic section, SIVOA used impervious upstream area. We will discuss this point in the hydrological analysis (Section 4.3.1).

The 1999 flooding produced a reinforcement of SC policies. The current regulation of the SIVOA (SIVOA, 2003) prescribes that:

"Stormwater collected at the scale of private parcels is not directly accepted in the sewer system. This water has to be infiltrated, regulated or treated. [...] the general rule is to search solutions allowing for the absence of stormwater runoff. [...] In cases where infiltration [...] demands disproportionate works, stormwater is stored and sent to the sewer system at a limited flow-rate." (translated by the authors). 
The limited flow-rate is set to $1 \mathrm{l} \mathrm{s}^{-1} \mathrm{ha}^{-1}$ for a rain event of $55 \mathrm{~mm}$ in $4 \mathrm{~h}$, corresponding to a 20-year return period (SIVOA, 2003). The 2003 regulation results, thus, from the superposition of a "no-runoff" prescription over the pre-existing $1 \mathrm{l} \mathrm{s}^{-1} \mathrm{ha}^{-1}$ limit.

The superposition of an infiltration prescription before a constraint on flow-rate is a diffusing practice in France. It is based on the idea that reducing runoff volume is even better than reducing flow-rate. However, in this case like in many others, infiltration is left vague, while flow-rate constraint is clearly defined and quantified. For SIVOA, no-runoff is "the general rule", and the developer should find by himself the way to realize it; if these ways appear "disproportionate", the developer can apply the ready-to-use storage volumes. According to the authors' opinion, the risk connected with this formulation is that in the absence of a clear (and rigid) praxis of what "disproportionate" means, most developers will chose the easiest way to cope with regulation and build ponds. The infiltration prescription will be ignored in most developments.

\subsection{The Schéma Directeur d'Aménagement et de Gestion des Eaux Seine-Normandie, 2010-2015}

From the point of view of watersheds' management, the entire France is divided into six parts, and for each a Schéma Directeur d'Aménagement et de Gestion des Eaux (SDAGE) is elaborated (Fig. 2).

The current version of the SDAGE (2010-2015) Seine-Normandie (Comité de Bassin Seine-Normandie, 2009) prescribes, for urban areas, the development of stormwater zoning that "can define criteria relative to [...] maximal flow-rate". While this tool is already provided-without specific quantification-by French law, the SDAGE fixes a "default value":

“[...] In the absence of studies or local doctrines determining [an acceptable downstream flow-rate], it will be limited to $1 \mathrm{ls}^{-1} \mathrm{ha}^{-1}$ for a storm event having a return period of 10 years. [...] In order to prevent floods and to take into account the natural water cycle, zoning regulations should foster infiltration of stormwater and restoration of pervious soils." (translated by the authors).

As discussed in Section 2, there is growing consensus about the necessity of local and specific regulations of stormwater management. The SDAGE recognizes this necessity when it calls for local studies and doctrines but, at the same time, it sets a general standard of $11 \mathrm{~s}^{-1} \mathrm{ha}^{-1}$ for a 10 -year storm. An interview with a member of the technical staff of AESN confirmed that the rationale of this default value comes more from communication than from hydrology:

"I think that, behind the display of this value [of $\left.1 \mathrm{ls}^{-1} h \mathrm{a}^{-1}\right]$, was the will to make things evolve. This means that 0, 1, 2-well, any low value - was not important by itself. The important thing behind the current formulation [...] is that stormwater management must be studied locally. [...] The unique value has no meaning. Well, it has a meaning only if you watch it as a really low value that pushes, by the constraints it creates, people to study what else can be done of intelligent." (translated by the authors).

This approach is perfectly coherent with the scope of a large-scale planning tool like the SDAGE: urban stormwater floods are a local problem that must be solved locally; the large-scale role is just to encourage and support good practices. However, from the point of view of our analysis, the fact of setting a low flow-rate value hides a major shortcut: what happens if people just apply the rule as it is? 
The answer to the question which is implicit in the SDAGE formulation is that people (or authorities) applying the rule as it is will provide an effort bigger than necessary, improving the situation even more than required. The underlying assumption is that oversized BMPs are always beneficial, and thus a low flow-rate value is always better than a higher one.

As a final remark, the question about the application of the rule "as it is" is not just hypothetical: past experiences of stormwater management rules showed that general numerical standards are often followed strictly, without adaptation (Chocat and et al., 1997, p. 693).

\subsection{Discussion}

Some observation about SC policies can be drawn from the three cases discussed:

- BMPs are "small-scale large reservoirs". SC policies, at least in France, are a direct descendant of large stormwater reservoirs. Even if the objective of SC policies is no more flood prevention alone, but also pollution control, receiving water protection and water cycle mimicking, many authorities still focus on flow-rates constraints while elaborating SC policies. Flood prevention and the other objectives are still considered as different topics. This duality is not limited to France: in the USA, stormwater ponds and LID are often described as different technical objects, having different purposes (Williams and Wise, 2006). In a catchment-scale approach to catchment's problems, all these techniques should be seen as parts of the same set of tools.

The situation is however evolving: in France, the diffusion of infiltration prescription is a positive signal, as well as the implementation of the first stormwater zoning including both flow-rate and volume quantified prescriptions (Mouy et al., 2007). In the USA, the 2000 Maryland Stormwater Design Manual integrates the two aspects in a unified dimensioning approach (Comstock and Wallis, 2003).

- SC is the sum of individual BMPs. Scale-transition between parcels and catchment is assumed to be linear. The approach followed to define parcel-scale constraints is, for Seine-Saint-Denis and SIVOA, to divide an admitted flow-rate by the upstream area. Beside the choice in the area measurement (total or impervious), this approach supposes that catchment-scale flow-rate is the sum of the flow-rates from parcels, ignoring all about scale effects like peaks' attenuation and delay.

Regulations demanding to preserve pre-development flow-rates, typical in the USA, are based on the same assumption (Petrucci and Tassin, 2011). The rationale behind them can be summarized as: "if every parcel of the catchment does not produce a runoff peak higher than the pre-development one, the whole catchment too will not produce a runoff peak higher than the pre-development one". Peaks' increased durations and consequent superpositions are ignored (Booth and Jackson, 1997; Goff and Gentry, 2006).

- Two BMPs are better than one. All the approaches analyzed make the implicit assumption that more BMPs have a better global effect than less, and thus that a more strict regulation is always more suitable than a less strict one. Both for Seine-Saint-Denis and SIVOA the precautionary choice is always the more strict. As discussed in Section 2, perhaps this assumption was acceptable in a pioneering phase of SC development, but in wide diffusion scenarios it has to be verified. Together with higher implementation costs, an excessive SC policy could involve negative side effects. 


\section{Hydrological analysis}

The object of the modeling part of this paper is the analysis of the catchment-scale effects of SC regulations, under the hypothesis that they are widely applied to a catchment. The purpose is to assess the long term consequences of the present SC regulations, as they emerged from regulations' analysis.

\subsection{Material and methods}

To compare scenarios of SC regulations, we use the hydrologic model of a catchment in the Paris region (Section 4.1.1). In order to have reliable simulations of the catchment behavior, a comprehensive setup, calibration and validation process (Section 4.1.3 and 4.1.4) is performed using the available data. In the analysis, we consider two types of scenarios: flow-rate limitations and volume limitations (Section 4.1.5). For each type, we consider variable constraint values. Scenarios are compared on the basis of three indicators (Section 4.1.6).

\subsubsection{The experimental catchment}

The ZOH catchment (Zone opérationnelle d'habitat, 451 ha, Fig. 3) is $20 \mathrm{~km}$ south of Paris, and it is mainly under the authority of SIVOA (Section 3.3 and Fig. 2). While municipalities own proximity stormwater collectors on their territories (not modeled in the current study), SIVOA is in charge of the major collector.

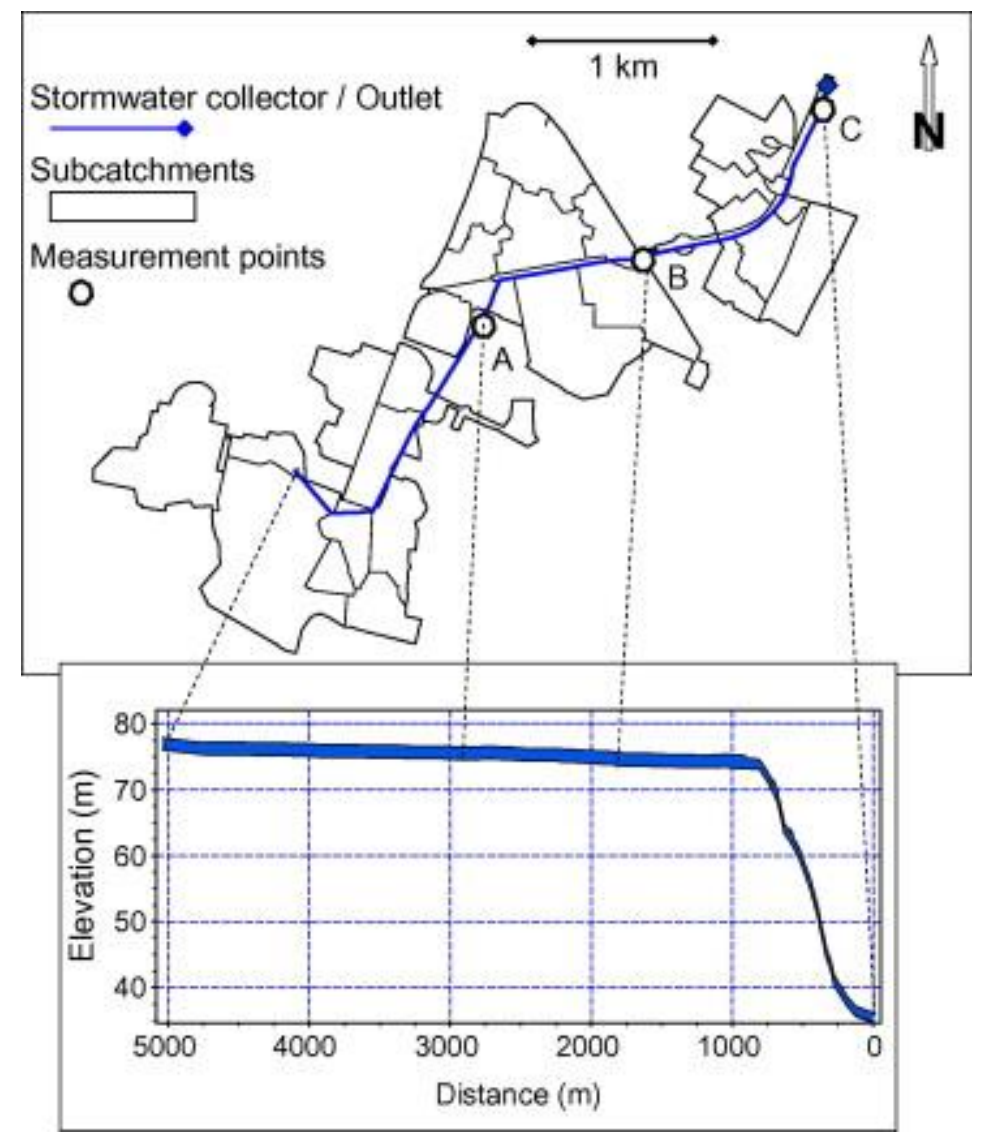

Fig. 3. Plan of the $\mathrm{ZOH}$ catchment and main collector's profile.

Topographically, the catchment is on a plateau (see collector's profile in Fig. 3): its upstream two-thirds have small slopes $(<0.5 \%)$, while the downstream part - on the hillside - is much steeper $(5-6 \%)$. The catchment was rural until 1960 and drained by small creeks. Since the construction of the main collector from the SIVOA (1968/1969), 
many urban developments took place and were connected to it. Impervious cover in the catchment is approximately $30 \%$, and urbanization of the area is still in progress. Most of the urban development occured before the enforcement of the actual SC regulation and, thus, it is equipped with conventional drainage. This type of plateau development - and in particluar its drainage conditions - is typical of the urbanization of the second half of the 20th century in the Paris region and in other French urban areas (Bergue and Ruperd, 1994; carre, 2002). The behavior of the considered catchment, therefore, can be considered representative of several periurban catchments in France.

The stormwater outlet is connected to a group of small sand-pit lakes linked to the Seine river. The outlet is equipped, since 2003, with a settling unit to protect the lakes from suspended solids and eutrophication (Catherine et al., 2008).

\subsubsection{Model choice and characteristics}

The model used to perform the analysis is SWMM 5 (Rossman, 2004). It is a widely diffused urban hydrology model, flexible and well suited to represent BMPs (Carter and Jackson, 2007; Elliott and Trowsdale, 2007; Gironás et al., 2009).

Elliott and Trowsdale, 2007 review ten different models suitable for SC modeling. They discuss a set of features of these models that should drive the choice of one specific model depending on the purpose of the study. Among others, they cite temporal resolution and scale, spatial resolution and scale, representation of runoff generation and routing.

The choice about temporal parameters and processes' representations depends on the variables of interest: if the model should well describe hydrographs' peaks in sewers, the modeling time-step should be short and hydrographs' routing detailed. In urban areas, peaks are mainly driven by direct runoff on impervious areas and sewer routing (Chocat and Cabane, 1999; Rodriguez et al., 2003). Overland flow on a $10^{2}-10^{3} \mathrm{~m}$ scale, according to Blöschl and Sivapalan (1995), corresponds to temporal scales smaller than one hour. Flow in the sewer system is even faster. We adopted a reporting time step of $5 \mathrm{~min}$, while routing calculation (integration of de Saint Venant one-dimensional equations) is performed on shorter and varying time steps ( $<60 \mathrm{~s})$. On the opposite, to model the global hydrological balance, a so high resolution is not necessary ( $1 \mathrm{~h}$ or even 1 day is a typical time step, Mitchell et al., 2001), but time scale is relevant: to account for a catchment water balance, the model has to simulate long periods (one or more years). Some recent researches on SC (e.g. Zimmer et al., 2007) use a combined approach, simulating both single rain events and long time-series. To have a broader view of SC policies, we adopted the same approach. SWMM is adapted to this use, as it allows continuous simulations over long periods with short time steps.

From a spatial scale and resolution point of view, SWMM describes the catchment as a set of subcatchments and a drainage network. Subcatchments, whose size and number (i.e. spatial resolution) depend on the modeler's choice, are in charge of runoff generation, while the network accounts for routing processes.

Each subcatchment is described as a non-linear reservoir, with an outflow equation given by the kinematic wave model (Singh, 1988). The model takes into account initial losses, and evaporation is computed at each time step on the basis of a monthly average. Infiltration from pervious areas is described by the Green-Ampt model. 
Subcatchments can be split in two parts: impervious and pervious. Runoff from one part can be routed over the other. Subcatchments are linked to a node of the sewer network: at each time-step the outflow of the subcatchment is injected in the corresponding node and routed in the network. Special devices can be added to the sewer network, like reservoirs, outlets and weirs.

Simulations' outputs are the values, at the reporting time-step, of relevant variables for all subcatchments and elements of the sewer network.

\subsubsection{Model setup}

Model setup involves the division of the catchment in subcatchments and the corresponding data-analysis to define each subcatchment's characteristics.

The division in subcatchments (32, Fig. 3) has been made according to catchment topography and sewer network. Subcatchments' characteristics (area, slope, pervious ratios, roof versus road area, etc.) have been determined by maps and aerial photos of the catchment.

Differently from most cases in the literature - see for example the manual of SWMM applications by EPA (Gironás et al., 2009) — we did not considered each "real" subcatchment as a "modeled" subcatchment, but we parted it in four areas according to land-cover. For each subcatchment on the ground, we defined four subcatchments in the model corresponding to green-, roof-, road- and "other"-areas. An example of the model structure is shown in Fig. 4. This strategy has two main reasons:

1. to take into account differences among impervious areas. Average slope and flowpath length for roofs are not the same than for roads, and describing roofs and roads as different subcatchments allows to parametrize them differently.

2. To take into account uncertainties in subcatchments' characteristics. Pervious area on a subcatchment is determined by pixel classification on aerial photos. This process involves some error, and lets some areas unclassified. The "other" areas correspond to unclassified ones, and are used to compensate this uncertainty: in the model they are partially pervious and partially impervious, and the ratio is determined through calibration to better fit runoff data.

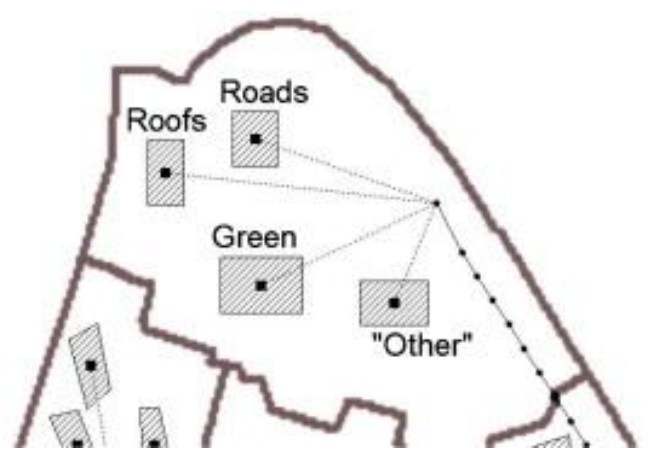

Fig. 4. Example of the model of a subcatchment.

This approach has already been used with good performances for a previous case-study, described in Petrucci et al., 2012.

4.1.4. Model calibration and validation 
Calibration and validation phases were performed on data issued from two flow-rate measurement campaigns operated by SIVOA in 2009 and 2010. Two three-month campaigns were performed at a 5-min frequency, the first from October to December 2009, the second from May to July 2010. The 2009 campaign involved one measurement point (point B in Fig. 3), while the 2010 campaign used two points (A and C). Rainfall data were issued from a rain gauge installed over the settling unit, at the catchment's outfall.

Data analysis showed that data collected on point $\mathrm{C}$ were of poor quality: they are affected by strong measurement noise (Fig. 10) and some missing value. Because of the importance of point C, downstream of all subcatchments, we decided to use these data anyway, after filtering and correction, still considering them less reliable.

The model parameters to calibrate are of two types: global, which are valid for the whole catchment, and local, valid for individual subcatchments. The global parameters are eleven: sewer roughness, soil characteristics (suction head, conductivity, initial deficit), initial losses and roughness for green, roofs and roads areas, impervious ratio of "other" areas. Only one local parameter, defined at the subcatchment scale, is used for calibration: the subcatchment width, a shape parameter (Singh, 1988; Rossman, 2004). We defined, for each parameter, a variability interval as narrow as possible according to hydrologic literature and catchment specific informations (e.g. soil type is mainly loam).

While global parameters, assumed to be unique over the catchment, can be calibrated on any rainfall-runoff time series, the local parameter for a given subcatchment can be calibrated and validated only, obviously, on runoff data measured downstream of it. As available data are collected at three different points, to use all of them we performed a three-step calibration and validation:

1. Calibration and validation of all the global parameters and of the local parameters for the subcatchments upstream of point B. Calibration was performed on two thirds of the data from the 2009 campaign; validation on the remaining third.

2. Validation of global parameters on data from the 2010 campaign (point A). In this validation, also local parameters of subcatchments upstream of point $A$ are validated.

3. Calibration and validation of local parameters for subcatchments between point $B$ and $C$, on data from the 2010 campaign (point C). Two-thirds of data were used for calibration, the remaining third for validation.

All calibrations and validations used, as a goodness-of-fit measure, the Nash criterion (Nash and Sutcliffe, 1970):

$$
N=1-\frac{\sum_{t}\left(Q_{t}-\widehat{Q}_{t}\right)^{2}}{\sum_{t}\left(Q_{t}-\bar{Q}\right)^{2}}
$$

where $Q_{\mathrm{t}}$ and $\mathrm{Q}^{\wedge} \mathrm{t}$ are respectively the observed and simulated flow-rates at time $t$, and $\mathrm{Q}^{-}$is the observations' mean value. This indicator ranges from $-\infty$ to 1 , with higher values for more accurate models. A value of 1 denotes a model perfectly matching the observed data, while a value of 0 denotes a model as accurate as the observations' mean value.

Calibrations were performed using a genetic algorithm. This type of evolutionary algorithm has been used for hydrologic models' calibration or optimization during the last 20 years and it is now well diffused in hydroinformatics' applications (Savic and Khu, 2005). The main interest of this algorithm is its efficiency in 
finding close-to-optimal solutions of high-dimensional optimization problems, without strong hypotheses on the problem setting (e.g. linearity or continuity of the objective function).

\subsubsection{Scenarios of SC policies}

Flow-rate limitations. Scenarios of regulations limiting flow-rate are in the form $q^{*}=x 1 \mathrm{~s}^{-1} \mathrm{ha}^{-1}$ typical of French cases. We simulate 15 scenarios, ranging from $q^{*}=0.51 \mathrm{~s}^{-1} \mathrm{ha}^{-1}$ to $501 \mathrm{~s}^{-1} \mathrm{ha}^{-1}$. The lower part of the range $(0.5-$ $10 \mathrm{~s}^{-1} \mathrm{ha}^{-1}$ ) corresponds to current practices in France (and also in the UK, according to Faulkner, 1999), while the upper limit $\left(50 \mathrm{ls}^{-1} \mathrm{ha}^{-1}\right)$ is chosen in order to include the reference value of the specific peak flow-rate $\left(46 \mathrm{l} \mathrm{s}^{-1} \mathrm{ha}^{-1}\right)$.

Flow-rate limitations are modeled by installing a reservoir downstream of the roof and road areas of each subcatchment (Fig. 5). Each reservoir has an outfall and a spillway, both connected to the sewer network. Spillways are over-sized, in order to allow reservoirs' overflow to reach the sewer. Reservoirs' volume and outfalls' stagedischarge curve vary according to $q^{*}$. Reservoirs' volume is calculated using the rainfall design method (Chocat and et al., 1997, p. 627) for the SIVOA's design rain-event (triangular, $55 \mathrm{~mm}$ in $4 \mathrm{~h}$, see Section 3.3). Specific volumes for each scenario are reported in Table 1.

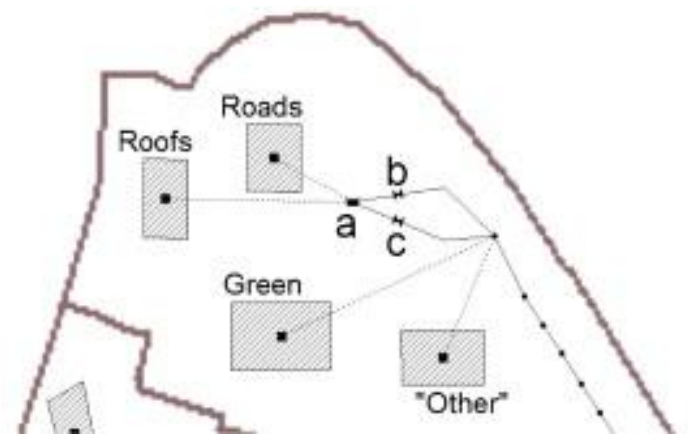

Fig. 5. Model of a subcatchment with flow-rate limitation. (a) reservoir, (b) reservoir's outfall, and (c) reservoir's spillway.

Table 1. Flow-rate regulations and corresponding storage volumes.

\begin{tabular}{|llllllllllllllll}
$\mathbf{q} *\left(\mathbf{l ~ s}^{-1} \mathbf{h a}^{-\mathbf{1}}\right)$ & $\mathbf{0 . 5}$ & $\mathbf{1}$ & $\mathbf{2}$ & $\mathbf{3}$ & $\mathbf{5}$ & $\mathbf{8}$ & $\mathbf{1 0}$ & $\mathbf{1 5}$ & $\mathbf{2 0}$ & $\mathbf{2 5}$ & $\mathbf{3 0}$ & $\mathbf{3 5}$ & $\mathbf{4 0}$ & $\mathbf{4 5}$ & $\mathbf{5 0}$ \\
$\mathrm{v} *\left(\mathrm{~m}^{3} \mathrm{ha}^{-1}\right)$ & 658 & 565 & 485 & 447 & 377 & 323 & 299 & 262 & 252 & 231 & 205 & 184 & 168 & 155 & 145
\end{tabular}

SWMM allows to use stage-discharge curves in the form:

$$
Q=a h^{b}
$$

where $Q$ and $h$ are, respectively, the reservoir's outflow and water level. Parameter $a$ defines flow-rate magnitude, while $b$ the steepness of the curve. Fig. 6 shows an adimensional plot of this curve for two values of $b$. In principle, a small value of $b$ could assure a step-shaped curve: even for small water levels, the outflow is close to the regulation value. However, some tests showed that this choice produces numerical instabilities in the model. If the curve is too steep, in fact, for small stored volumes emptying is too fast and a discontinuous behavior takes place. The consequence is oscillating values of stored volume and outflow. This saw-tooth profile has a low magnitude (10-3m3s-1), but produces substantially wrong results for the computation of low flows. Thus, our choice for $b$ was 
a compromise between steepness and numerical stability. The selected value is $b=0.3$, that gives consistent values, for $q^{*}<151 \mathrm{~s}^{-1} \mathrm{ha}^{-1}$.

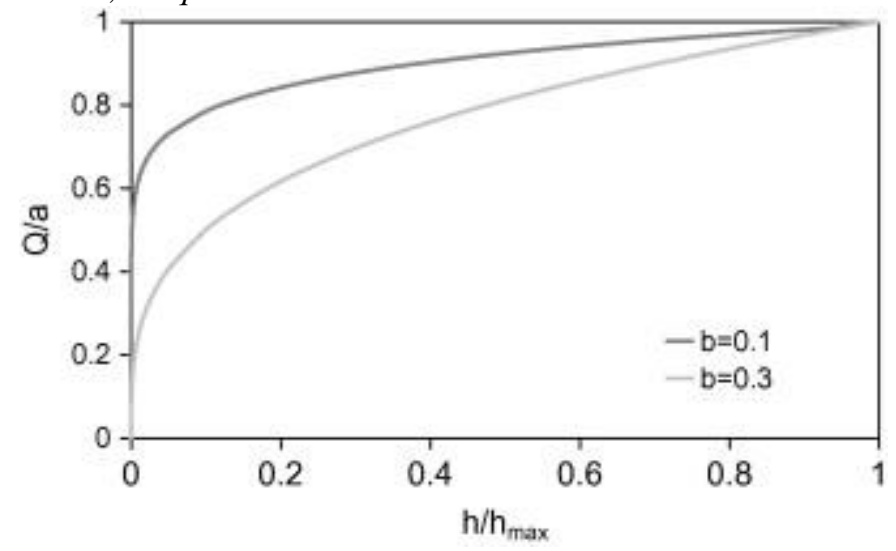

Fig. 6. Adimensional stage-discharge curve.

Parameter $a$ is defined, for each reservoir, as:

$\mathrm{a}=\mathrm{q}^{*} \cdot \mathrm{A}_{\text {drained }}$

where $A_{\text {drained }}$ is the impervious area contributing to the reservoir.

Volume limitations. SC scenarios with limitations on runoff volume are defined by the specific volume to be retained $i^{*}=x \mathrm{~mm}$. It is the regulation form applied in Paris $(4-12 \mathrm{~mm})$ and in Sun City, Arizona (19mm). We consider 18 scenarios, ranging from $i^{*}=0.01 \mathrm{~mm}$ to $i^{*}=50 \mathrm{~mm}$. The first half of the range corresponds to the cited existing policies, while the second half is to explore the potential of stronger regulations.

Volume regulations are modeled as filter strips downstream of each impervious subcatchment (roads and roofs), that store and infiltrate the prescribed volume of runoff from the impervious area. A scheme of the modified subcatchments' model is presented in Fig. 7. If the subcatchment has an area $A_{\mathrm{s}}$, the strip stores (as initial losses) a runoff volume of $\mathrm{v}=\mathrm{Asi} *$. This water is then infiltrated and can be replaced by further runoff.

\section{Remark 1}

The two different forms of regulation are defined according to the current practices. It is important to note that, using $q^{*}$ and $i^{*}$ as defined, they vary in opposition: stronger regulations (i.e. regulations demanding more resources to comply with) lead to lower values of $q^{*}$ and to higher values of $i^{*}$.

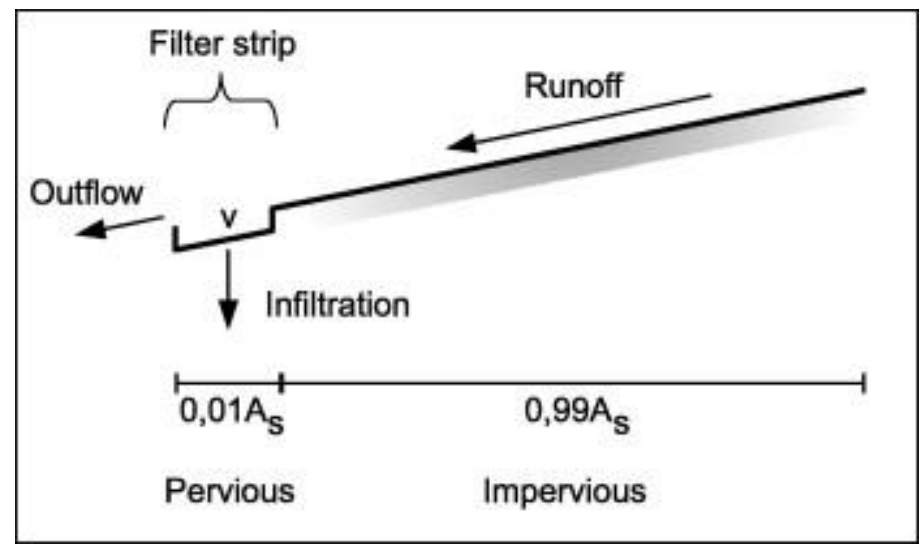

Fig. 7. Scheme of a subcatchment's model with volume regulation. 


\subsubsection{Policies' performance indicators}

To assess the performances of SC policies, Fennessey et al., 2001 used a "flow versus frequency" curve calculated on a long-term simulation. An example is the reference curve in Fig. 8, computed for the ZOH calibrated model on a 23 -month period (1/1/2009 to $1 / 12 / 2010)$. The main advantage of a similar approach is the immediate visibility of changes in flow regimes both for extreme events and low flows. Indeed, the intersection between the curve and the $y$-axis shows the maximal peak-flow during the computation period, while the intersection with the $x$-axis shows the fraction of time during which a flow is detected at the outlet.

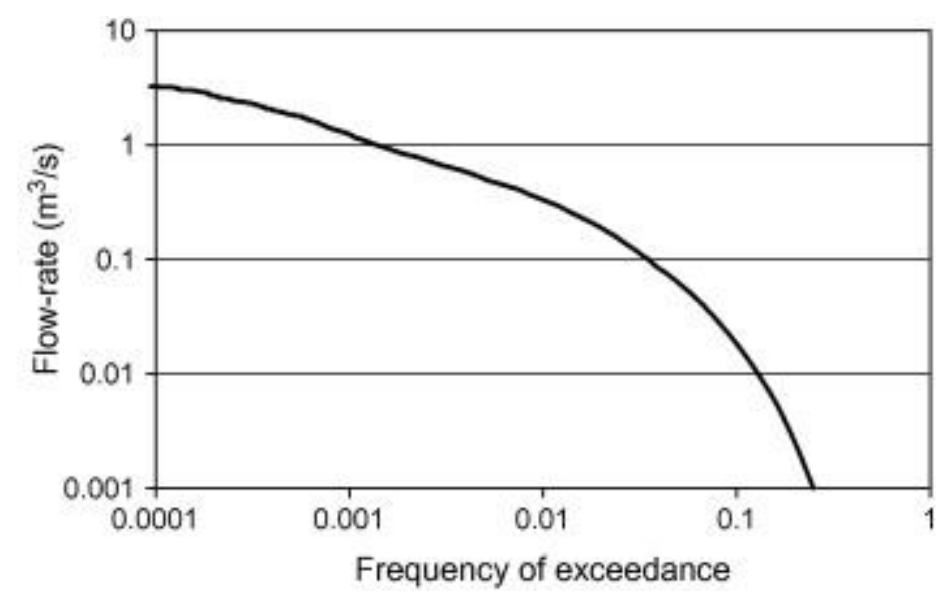

Fig. 8. Example of flow-frequency curve.

Beside the graphical approach and in order to compare a large number of scenarios, it is useful to define numerical indicators. With this purpose, we considered two typical objectives for SC policies: to avoid sewer overflows and to preserve receiving waters.

For the first objective, we used the peak flow-rate in response to the SIVOA's design rain event, the same used for reservoir's dimensioning in flow-rate limitation scenarios. Thus, to evaluate the first objective, the indicator chosen is the peak flow-rate for this rain event, normalized on the impervious area of the catchment (141 ha). This indicator is noted $q_{\text {peak }}\left(\mathrm{l} \mathrm{s}^{-1} \mathrm{ha}^{-1}\right)$; smaller values denote better performances.

As the stability and ecological status of the receiving waters depend, in general, both on low-flow regimes and on bypasses of treatment units, for the second objective we adopted two indicators: the fraction of time during which a flow is detected at the outlet (i.e. the frequency of flow), and the runoff volume bypassing treatment. The first is the $x$-axis intersection in flow-frequency curves, and it is noted $f_{\text {flow }}(-)$. The second is the total volume of flow exceeding $0.8 \mathrm{~m} 3 \mathrm{~s}-1$, which is the settling unit capacity. It is noted $V_{0.8}\left(\mathrm{~m}^{3}\right)$. Considering the actual imperviousness of the catchment, $0.8 \mathrm{~m}^{3} \mathrm{~s}^{-1}$ correspond to $5.7 \mathrm{l} \mathrm{s}^{-1} \mathrm{ha}^{-1}$. We consider that, for both indicators, smaller values denotes better performances.

$V_{0.8}$ is the more pertinent indicator for the $\mathrm{ZOH}$ catchment, as low-flow regimes are not considered a problem for the downstream lakes. However, as $f_{\text {flow }}$ can be relevant for similar catchments, according to the outfall characteristics, both are considered in the analysis with a purpose of generality.

For the numerical problems on low flows discussed in Section 4.1.5, $f_{\text {flow }}$ is not computed for $\mathrm{q} *>15 \mathrm{ls}^{-1} \mathrm{ha}^{-1}$. $f_{\text {flow }}$ and $V_{0.8}$ are computed for a 23 -month rainfall series (1/1/2009 to $\left.1 / 12 / 2010\right)$. The series 
is not long enough to give statistically relevant results for return periods longer than 1 year, but it is sufficient for current rain events ( $T<3$ months). The reference case used for comparison is the calibrated model, as we have no information on the pre-development catchment.

\subsection{Outcomes of calibration and validation}

The calibration process involved three steps (Section 4.1.4): calibration of global parameters and of local parameters of the upstream part of the catchment (2009 data); validation on 2010 upstream (point A) data; calibration and validation of local parameters for the downstream part of the catchment (2010 data, point C).

Figs. 9 and 10 shows samples of the simulated hydrographs, plotted against data. The values of the Nash criterion obtained are:

- $N=0.78$ for the calibration on 2009 data (point B), $N=0.75$ for the corresponding validation;

- $N=0.77$ for the validation on 2010, point A data;

- $N=0.56$ and $N=0.48$, respectively, for calibration and validation on 2010 , point $\mathrm{C}$ data.

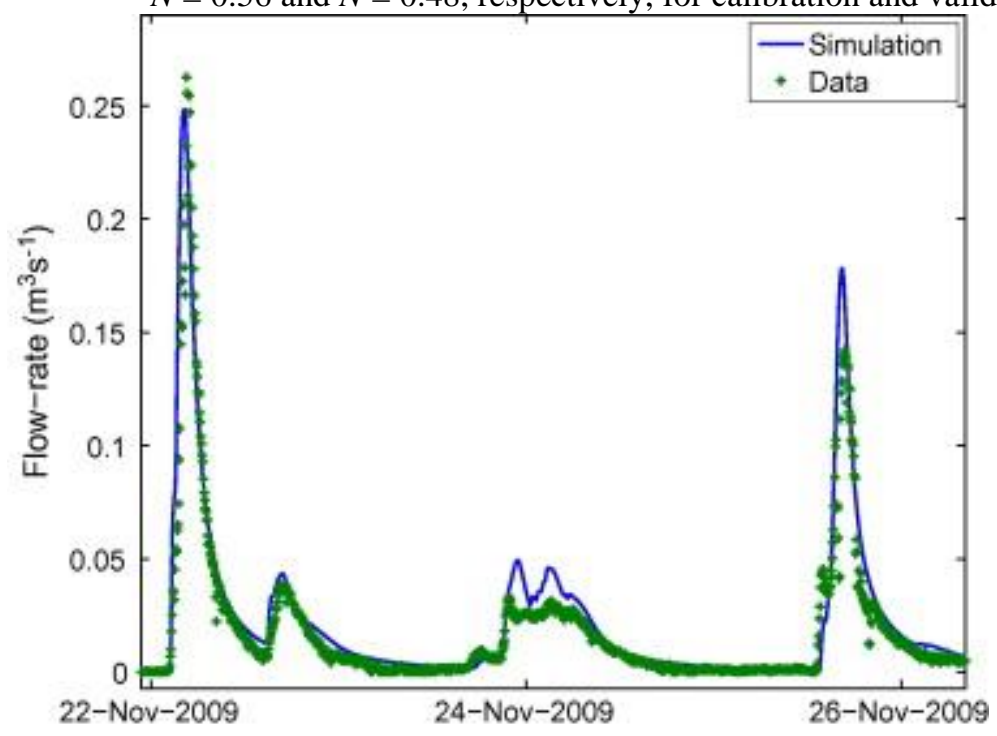

Fig. 9. Comparison between simulated and measured flow-rate. Point B, validation. 


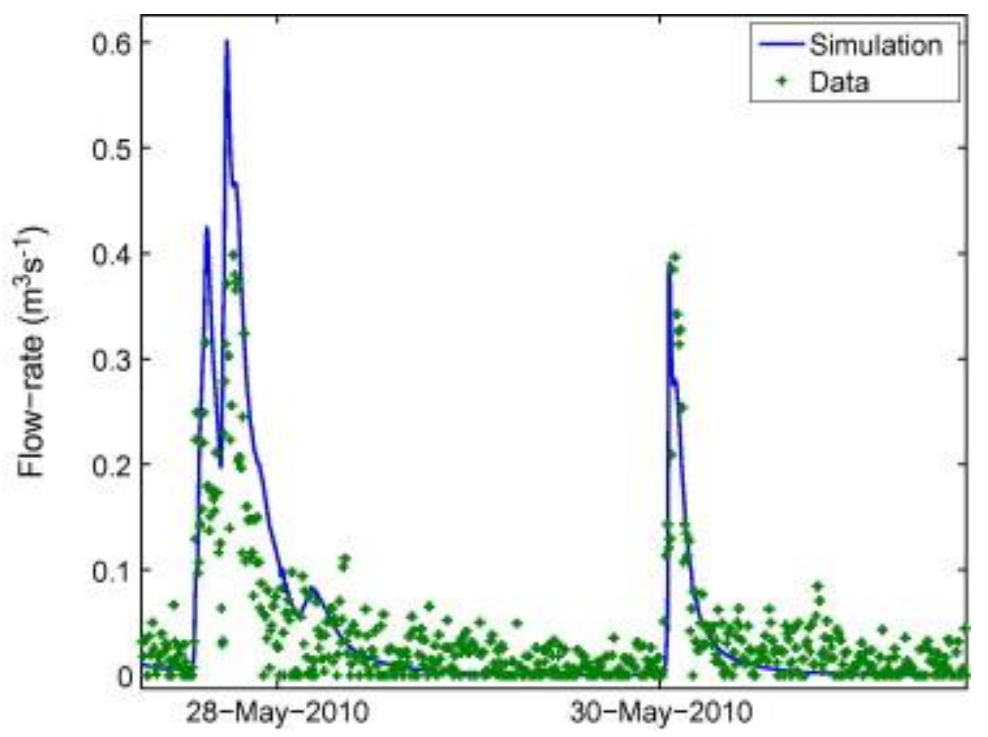

Fig. 10. Comparison between simulated and measured flow-rate. Point C, calibration.

A Nash value close to 0.8 denotes a good performance of the model. Considering also visual verification (Fig. 9), we can consider that the first calibration and the corresponding validation are satisfactory. Further, the validation on point A data shows that global parameters are well suited to describe the catchment behavior even in a season different from that used for calibration. 2009 data are collected in autumn, while 2010 ones are collected in spring and summer. Another positive result is that this validation is performed on a point of the catchment (A) which is upstream of the calibration point (B). Thus, the calibrated model is a good representation of the catchment not only globally (i.e. for runoff estimation at the calibration point) but also for estimation of runoff at internal points of the catchment.

The results obtained by the last calibration and validation (point C) show a worse correspondence between measurements and simulations. It is reasonable to suppose that this poor performance is more linked to the poor reliability of measurements (Fig. 10), than to modeling errors. The modeling procedure is, in fact, the same that performs well for the rest of the catchment. Still, without other datasets on point $\mathrm{C}$, it is impossible to know the actual accurateness of the model for the subcatchments between point $\mathrm{B}$ and point $\mathrm{C}$ (about $19 \%$ of the catchment area). As our purpose is analyzing scenarios, we can accept the calibrated model as a good representation of the entire catchment. If the purpose was to actually decide a policy for the catchment, a further measurement campaign at point A should be necessary.

\subsection{Results and discussion}

In Fig. 11 and 12 several flow-frequency curves are plotted and compared to the reference. The two figures reveal the different behaviors of the two regulations:

- Volume regulations (Fig. 11) have flow-frequency curves always lower than the reference. This means that, for any given frequency, the corresponding flow-rate will be smaller in presence of this kind of regulations. Obviously, low constraint values (e.g. $5 \mathrm{~mm}$ ) affect strongly the frequent events $(f>0.01)$, while infrequent ones $(f<0.001)$ are less changed. Increasing the constraint value $(25 \mathrm{~mm}$ and $50 \mathrm{~mm}$ in Fig. 11) further reduces flow-rates. Also infrequent events are affected by high constraint values. 
- On the contrary, flow-rate regulations (Fig. 12) have different effects for low and high frequencies. In fact, their flow-frequency curves have intersections with the reference curve. A reduction in low frequency flow-rates corresponds to an increase of flow-rates for higher frequencies, resulting in a "flattening" of the flow-frequency curve. Decreasing the limitation value (i.e. strengthening the constraint, as explained in paragraph 1) increases this "flattening" effect: the $1 \mathrm{~s} \mathrm{~s}^{-1} \mathrm{ha}^{-1}$ flow-frequency curve is almost flat for $f<0.1$, with flow-rates lesser than the reference for $f<0.03$, and higher elsewhere.

The values of the three indicators, for all the simulated SC scenarios, are plotted in Figs. 13-15. According to the final remark of Section 1, they are plotted on inverse axes to show results in the same order: in the positive $x$ direction regulations" "strength" increases.

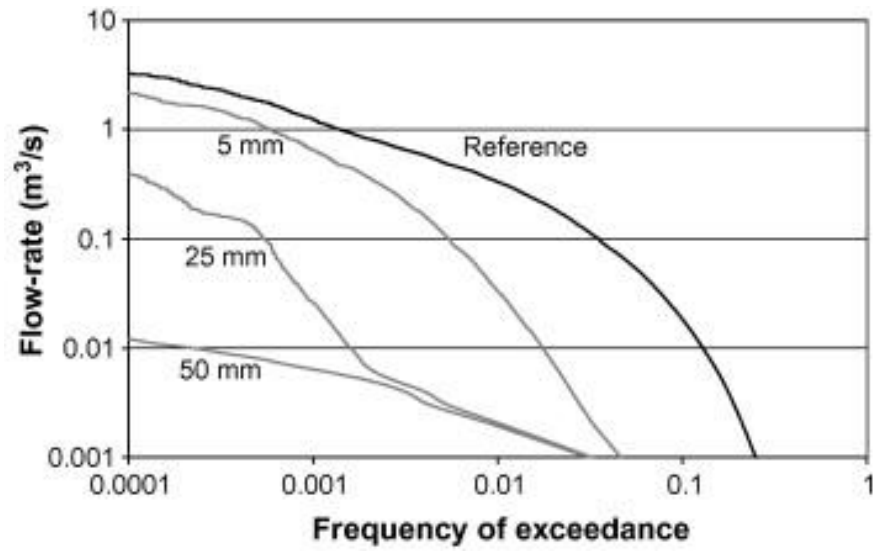

Fig. 11. Flow-frequency curves for a selection of volume regulation scenarios.

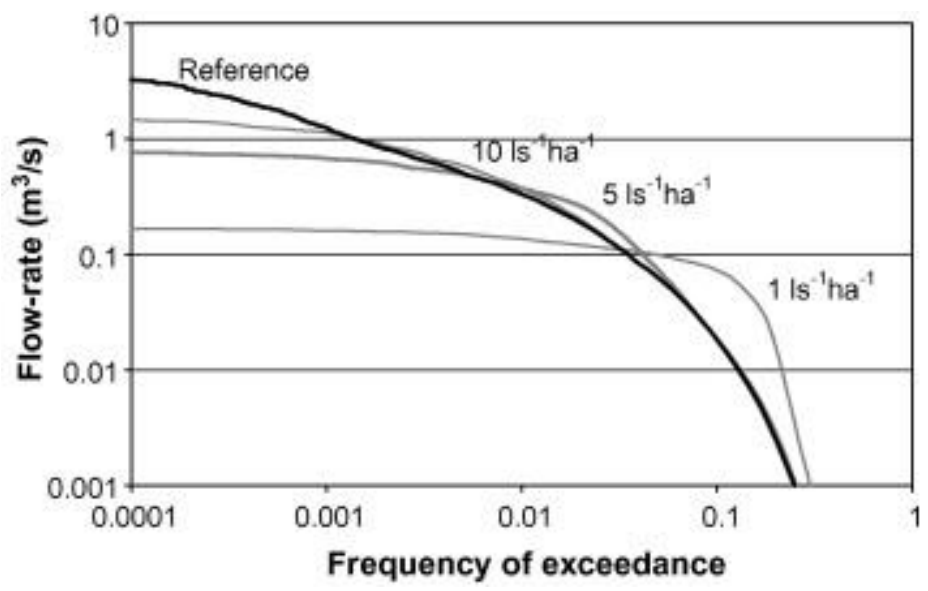

Fig. 12. Flow-frequency curves for a selection of flow-rate regulation scenarios. 


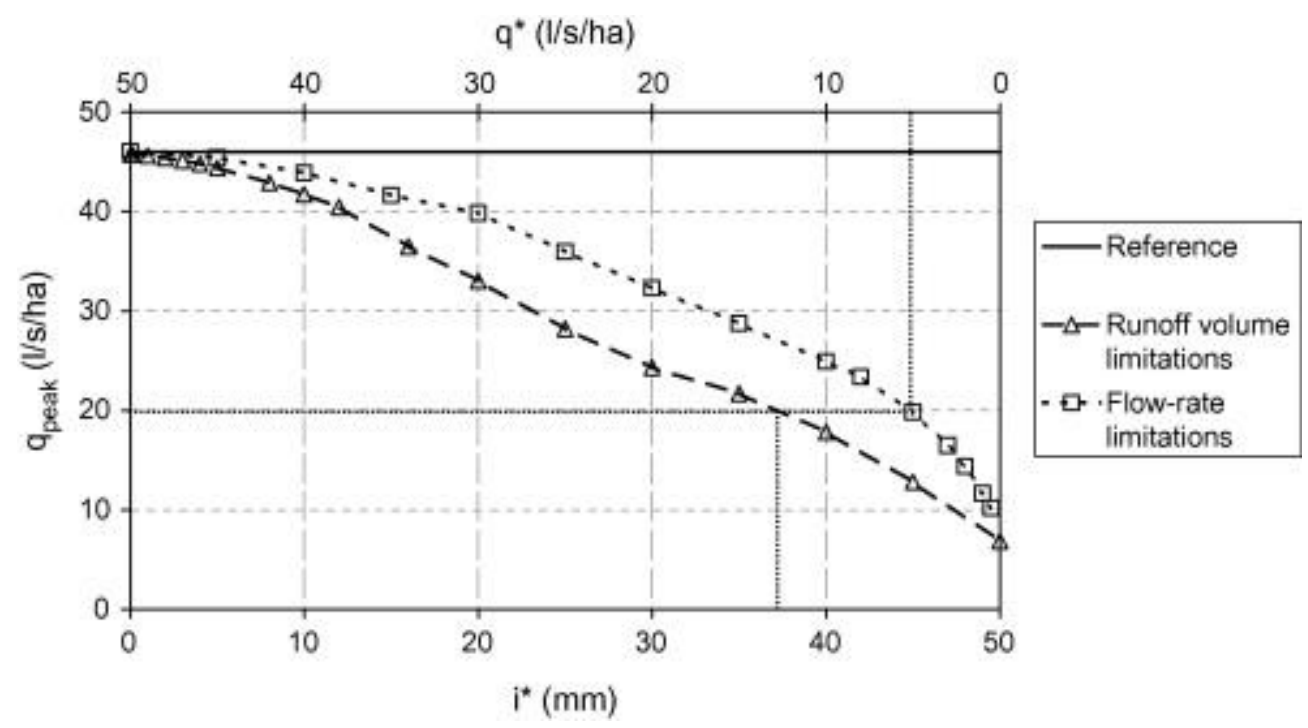

Fig. 13. qpeak values as a function of flow-rate and volume constraints.

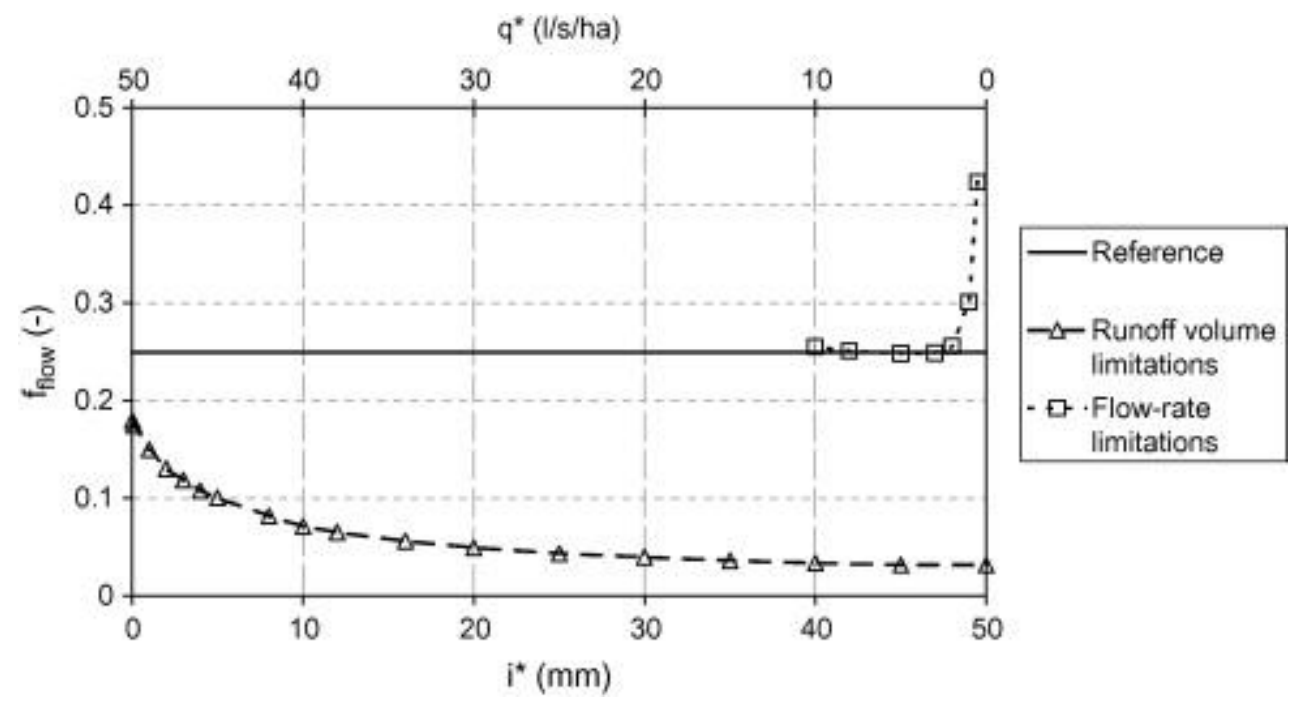

Fig. 14. $f_{\text {flow }}$ values as a function of flow-rate and volume constraints. For $\mathrm{q} * \geqslant 151 \mathrm{~s}^{-1} \mathrm{ha}^{-1}$, fflow is not computed.

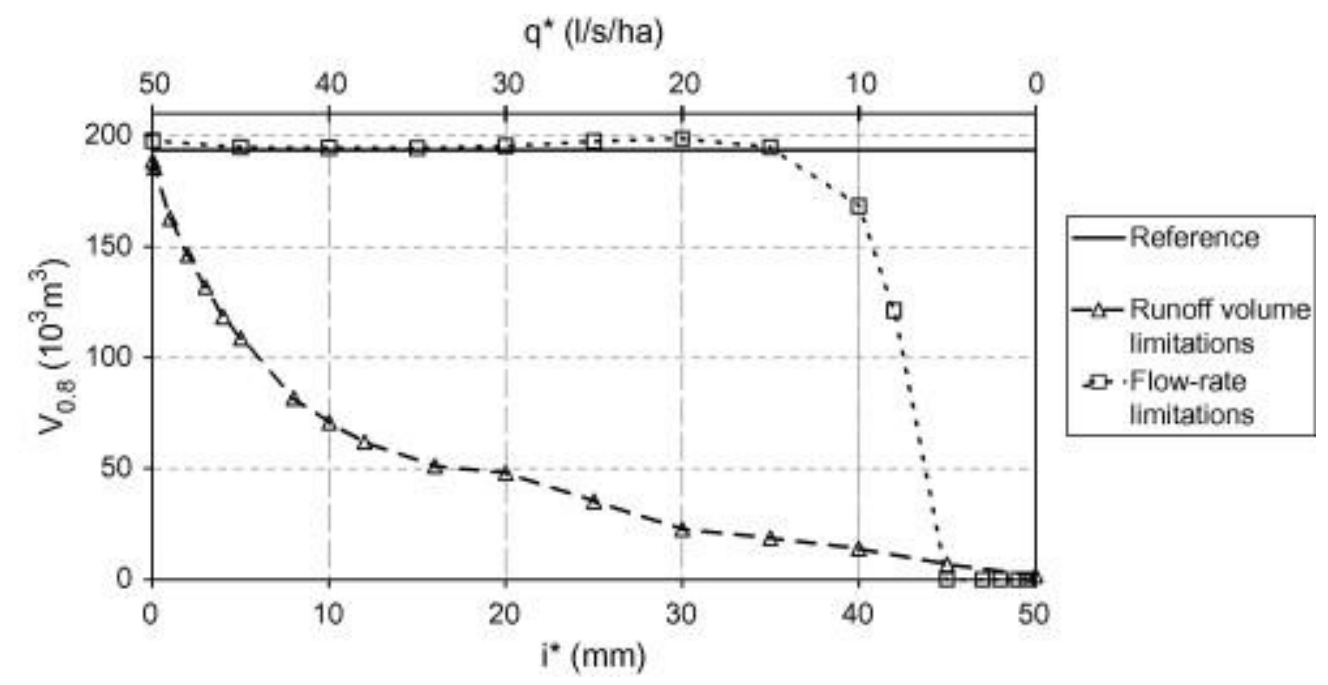


Fig. 15. $V_{0.8}$ values as a function of flow-rate and volume constraints.

\subsubsection{Reduction of sewer overflows}

This first objective (avoiding sewer overflows) is described by the indicator $q_{\text {peak }}$, as stated in Section 4.1.6. For both types of regulations, Fig. 13 reveals that $q_{\text {peak }}$ monotonously decreases with strengthening regulations. Thus, for both regulation forms, no worsening of catchment-scale peak flow-rate occurs with specific regulation values.

Comparing volume and flow-rate regulations shows that the corresponding ranges of $q_{\text {peak }}$ are about the same. Thus, for a given target value of the objective in this range (e.g. $q_{\text {peak }}=201 \mathrm{~s}^{-1} \mathrm{ha}^{-1}$ ), it is always possible to find two corresponding regulations, one based on limitation of flow-rate (in the example $q^{*}=51 \mathrm{~s}^{-1} \mathrm{ha}^{-1}$ ) and one on limitation of volume $\left(i^{*}=37 \mathrm{~mm}\right)$.

A further remark is that, for flow-rate regulations, $q_{\text {peak }}$ is greater than $q^{*}$. For intense rain events, in facts, pervious areas (not controlled by reservoirs) contribute significantly to the catchment-scale peak flow-rate. The procedure applied by the SIVOA to define $q^{*}$ (Section 3.3) was to divide a maximum acceptable flow-rate by the upstream impervious area: this corresponds to taking a value of $q^{*}$ on the $q^{*}=q_{\text {peak }}$ curve (plotted in Fig. 16). Because of the contribution of not controlled areas, this procedure leads to values of $q^{*}$ too high to assure the expected value of $q^{\text {peak }}$.

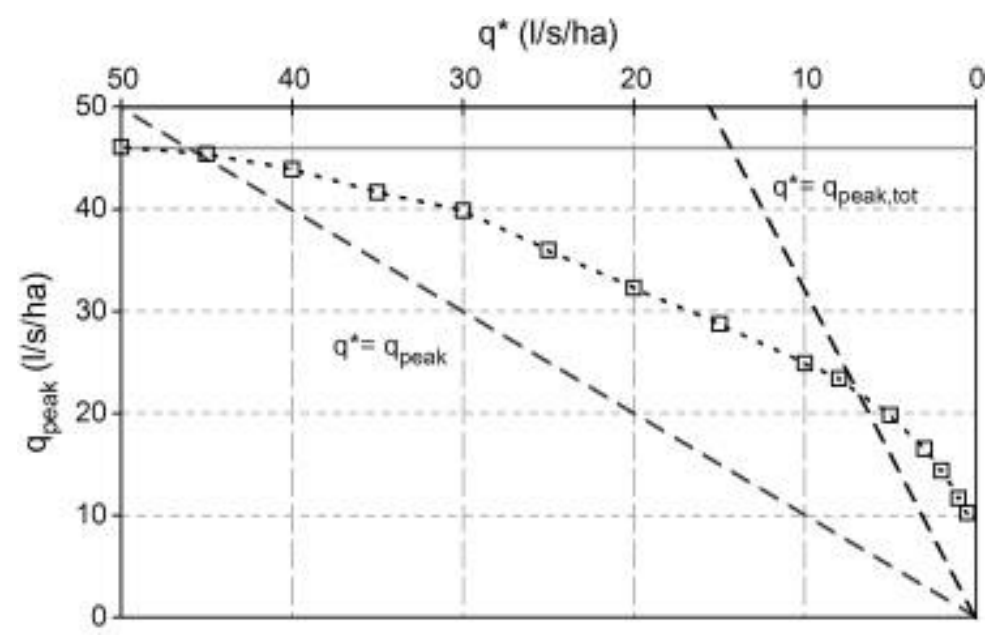

Fig. 16. $q_{\text {peak }}$ values for flow-rate regulations, compared to $q^{*}=q_{\text {peak }}$ and $q^{*}=q_{\text {peak,tot }}$ lines.

As a comparison with the Seine-Saint-Denis procedure, based on the total upstream area (Section 3.2), we plotted in Fig. 16 the curve $q^{*}=q_{\text {peak,tot. }} q_{\text {peak,tot }}$ is an indicator analogous to $q_{\text {peak }}$, but normalized on the total area of the catchment. This second curve shows the limits of a linear approach in SC regulation (Section 3.5): using the total area for the calculation is, intuitively, a highly precautionary procedure. Fig. 16 shows that this is true for high values of $q^{*}\left(>81 \mathrm{~s}^{-1} \mathrm{ha}^{-1}\right)$, for which the constraint is largely overestimated. But for low values of $q^{*}$, the total area procedure underestimates the values of the constraint like the impervious area one. More in general, this is an evidence of the unfitness of a linear approach to the transition from the parcel- to the catchment-scale for SC regulation.

\subsubsection{Preservation of receiving waters}

This second objective (preserving receiving waters) is described by the two indicators $f_{\text {flow }}$ and $V_{0.8}$ (Section 4.1.6). 
Fig. 14 shows flow frequencies at the catchment outlet (fflow). For the reference case, $f_{\text {flow }}=0.25$. As it was expected (Section 2), runoff rate limitations never improve the reference situation, while runoff volume ones always do. In detail, runoff rate regulations do not affect the indicator for $q^{*}>21 \mathrm{~s}^{-1} \mathrm{ha}^{-1}$, while for lower values they significantly worsen the situation (up to $f_{\text {flow }}=0.42$ ). In these last cases, the "flattening" of flow-frequency curves is marked enough to increase frequency of really small flow-rates (e.g. see the $1 \mathrm{l} \mathrm{s}^{-1} \mathrm{ha}^{-1}$ curve in Fig. 12). Physically, this phenomenon occurs when the emptying time of reservoirs is longer than the undisturbed hydrograph's duration. Thus, flow-rate regulations distort low-flow regimes only if they leads to reservoirs' emptying time longer than catchment-scale lag-times.

Volume regulations, on the contrary, rapidly improve the indicator value for $i^{*}<20 \mathrm{~mm}$. $f_{\text {flow }}$ is positively affected even for extremely small storage values $\left(i^{*}=0.01 \mathrm{~mm}\right)$, because of the infiltration effect of filter strips covering $1 \%$ of previously impervious areas, even without storage (see Section 4.1.5).

Volumes exceeding the treatment unit flow capacity (indicator $V_{0.8}$ ) are plotted in Fig. 15. Also for this indicator, volume regulations show a monotonous improving behavior, slowing down with increasing constraint values. As in the previous case, a small constraint (e.g. $i^{*}=6 \mathrm{~mm}$ ) is enough to half (from $1.93 \mathrm{e} 5 \mathrm{~m}^{3}$ to $0.82 \mathrm{e} 5 \mathrm{~m}^{3}$ ) the reference value of the indicator.

Flow-rate regulations have a more complex behavior, showing four different ranges:

- $q^{*}<51 \mathrm{~s}^{-1} \mathrm{ha}^{-1}$. The flattening effect causes the flow-rate to be always below $0.8 \mathrm{~m}^{3} \mathrm{~s}^{-1}$, and thus $V_{0.8}=0 \mathrm{~m}^{3}$.

- $51 \mathrm{~s}^{-1} \mathrm{ha}^{-1}<q^{*}<151 \mathrm{~s}^{-1} \mathrm{ha}^{-1}$. In this range the regulation shows a "good" behavior: strengthening the constraint improves values of the indicator.

- $151 \mathrm{~s}^{-1} \mathrm{ha}^{-1}<q^{*}<301 \mathrm{~s}^{-1} \mathrm{ha}^{-1}$. In this range, regulation produces worse performances than the reference case. The reason is that, during reservoirs emptying, the catchment flow-rate is above $0.8 \mathrm{~m}^{3} \mathrm{~s}^{-1}$ for longer durations than in the reference case.

- $q^{*}>301 \mathrm{~s}^{-1} \mathrm{ha}^{-1}$. No significant variation from the reference case.

\subsubsection{Flow-rate versus volume regulations}

Globally, results for the three indicators show that volume regulations have a simpler behavior than runoff rate ones. Indeed, volume regulations exhibit always a monotonous trend: strengthening the constraint generates improvements in the indicators' value. On the contrary, flow-rate regulations show threshold-effects and, for some ranges, can produce degradation of indicators value.

Obviously, these thresholds and the existence of degradation ranges are catchment specific: for example, regulations do not affect the $f_{\text {flow }}$ indicator if the emptying time of the reservoirs for a rain event is shorter than the duration of the corresponding hydrograph in the reference situation. In the same way, we find no aggravation ranges for $q_{\text {peak }}$ while other researchers did, for other catchments (Section 2).

This complex behavior of the flow-rate limitations appears to be linked to the flattening effect observed on the flow-frequency curves. The three indicators, even if with different formulations, are all linked to some specific part of these curves: $q_{\text {peak }}$ to high flow-rates, $f_{\text {flow }}$ to small ones, $V_{0.8}$ to intermediate ones. Flow-rates limitations do 
not reduce these curves systematically like volume ones, but filter high flow-rates increasing smaller ones. This is why substantial improvements of $V_{0.8}$ occur for values of $\mathrm{q}^{*}$ worsening $f_{\text {flow. }}$ Improving this last indicator is impossible with this form of regulation.

With regard to avoiding sewer overflows, we observed that the same $q_{\text {peak }}$ values that can be obtained through flow-rate regulations can also be obtained through volume ones. This remark can be discussed in the light of current practices. Current values of $q^{*}$ range from $0.51 \mathrm{~s} \mathrm{~s}^{-1} \mathrm{ha}^{-1}$ to $10 \mathrm{l} \mathrm{s}^{-1} \mathrm{ha}^{-1}$, while $i^{*}$ from $4 \mathrm{~mm}$ to $19 \mathrm{~mm}$ (Section 4.1.5). Comparing these ranges on Fig. 13 shows differing qpeak values: current values of $q^{*}$ lead to $q_{\text {peak }}$ values ranging from $10 \mathrm{l} \mathrm{s}^{-1} \mathrm{ha}^{-1}$ to $25 \mathrm{l} \mathrm{s}^{-1} \mathrm{ha}^{-1}$, while current values of $i^{*}$ to $q_{\text {peak }}$ values ranging from $33 \mathrm{l} \mathrm{s}^{-1} \mathrm{ha}^{-1}$ to $44 \mathrm{ls}^{-1} \mathrm{ha}^{-1}$.

If these results were confirmed for other catchments, it would be possible to infer that, according to the current practices, low peak flow-rates can be obtained only with flow-rate regulations. An authority facing problems of sewer overflows, and without the resources or the motivation to adopt "experimental" policies, can only limit flowrates. However, the evolution of flow-rate regulations in the last 30 years showed that, once the regulation principles are set, the constraint can be rapidly strengthened because the main impediments to SC regulations are more institutional barriers than technical difficulties. Today, a few authorities already apply runoff volume regulations with moderate constraints. It is possible that in a few years current practices will include stronger runoff volume limitations, able to cope also with sewer overflows.

\section{Conclusions}

SC policies have to be analyzed from a temporal perspective. This paper identifies, analyzing development of current policies, some actual trends in policy-making logics. The hydrological analysis assesses what will be the consequence of these trends if they continue to be applied in the long term.

The regulations' analysis revealed some shortcuts, that many regulators developing SC policies take instead of following a more hydrologically-sound reasoning. Two of the three shortcuts identified seem residuals of old approaches to SC: a persistence of the flow-rate approach and, more deeply, of a pioneer-approach oriented to develop as much and as larger BMPs as possible.

The hydrological analysis showed that SC policies based on these two shortcuts, applied together, can produce negative effects when widely applied on a catchment. In fact, we simulated "traditional" flow-rate regulations (i.e. flow-rate approach) and observed that strengthening the constraint (i.e. larger BMPs) aggravates the distortion of low-flow regimes.

While these two shortcuts are linked to decision-making inertia, the third one- a too simplistic concept of scaletransition - seems to be caused by the absence of appropriate hydrological tools to account for this transition. Today, the only available tool to evaluate SC policies on a specific catchment is detailed modeling, requiring conspicuous quantities of data, time, know-how and financial resources. Few local authorities, among all those that could be interested in adopting SC policies in the next years, are able to provide this effort.

Volume regulations, even if constrained by local infiltration possibilities, appear "safer" than flow-rate regulations for the authorities unable or reluctant to provide modeling effort: according to the analyses available and to our 
results, it seems that, for them, the approach "the more the better" is valid, as they do not seem to aggravate the situation in any case. Studying their application, consequences and practical limits on the catchments where they are already applied appears to be a priority. In the same time, their diffusion could be encouraged. More in general, studying SC policies effect at the catchment-scale seems a good approach to better understand the potential mitigations of the social and environmental impacts of urban growth, and to support regulators to reach a right balance between policy-making necessities and urban hydrology rationality.

Acknowledgments

The authors wish to express their gratitude to the many technicians who shared their competences and experience to help this research, and to their institutions. We particularly thank the SIVOA for making available the information and data on the $\mathrm{ZOH}$ catchment.

References

Azzout, Y., Barraud, S., Cres, F., 1994. Techniques alternatives en assainissement pluvial: choix, conception, réalisation et entretien. Technique \& Documentation, Lavoisier

C. Balascio, W. Lucas A survey of storm-water management water quality regulations in four Mid-Atlantic States J. Environ. Manage., 90 (2009), pp. 1-7

Bergue, J.M., Ruperd, Y. (Eds.), 1994. Guide technique des bassins de retenue d'eaux pluviales. Service Technique de l’Urbanisme, Ministére de l'Equipement. Technique \& Documentation, Lavoisier.

G. Blöschl, M. Sivapalan Scale issues in hydrological modelling: a review Hydrol. Process., 9 (1995), pp. 251290

Bollig, S.R., 2007. Diffusion of innovations: how local governments shape public policy to promote progressive stormwater management. Master's thesis. Department of Planning, Public Policy and Management of the University of Oregon.

D. Booth, C. Jackson Urbanization of aquatic systems: degradation thresholds, stormwater detection, and the limits of mitigation J. Am. Water Resour. Assoc., 33 (1997), pp. 1077-1090

Bourgogne, P., 2010. 25 ans de solutions compensatoires d'assainissement pluvial sur la communauté urbaine de Bordeaux. In: GRAIE, Novatech 2010, Lyon, France.

J.P. Cantone, A.R. Schmidt Potential dangers of simplifying combined sewer hydrologic/hydraulic models J. Hydrol. Eng., 14 (2009), pp. 596-605

Carré, C., 2002. Temps et systémes spatiaux: 'assainissement dans l'agglomération parisienne. L'Espace géographique 3, 227-240.

T. Carter, C. Jackson Vegetated roofs for stormwater management at multiple spatial scales Landscape Urban Plan., 80 (2007), pp. 84-94

A. Catherine, C. Quiblier, C. Yéprémian, P. Got, A. Groleau, B. Vinçon-Leite, C. Bernard, M. Troussellier Collapse of a planktothrix agardhii perennial bloom and microcystin dynamics in response to reduced phosphate concentrations in a temperate lake FEMS Microbiol. Ecol., 65 (2008), pp. 61-73

B. Chocat, P. Cabane Hydrologie urbaine: modélisation et effet d'échelle La Houille Blanche (1999), pp. 106111 
Chocat, B. et al., 1997. Encyclopédie de l'hydrologie urbaine et de l'assainissement. Eurydice 92. Technique \& Documentation, Lavoisier.

Chouli, E., 2006. La gestion des eaux pluviales urbaines en Europe: analyse des conditions de développement des techniques alternatives. Ph.D. thesis. Cereve, Ecole Nationale des Ponts et Chaussées, Paris.

Clar, M., Barfield, B., O’Connor, T., 2004. Stormwater best management practice design guide. US Environment Protection Agency. National Risk Management Research Laboratory, Office of Research and Development.

Comité de Bassin Seine-Normandie, 2009. Schéma Directeur d'Aménagement et de Gestion des Eaux 2010-2015. <http://www.eau-seine-normandie.fr/index.php?id=6131> (visited 07.11).

Comstock, S., Wallis, C., 2003. The Maryland stormwater management program: a new approach to stormwater design. In: National Conference on Urban Stormwater: Enhancing Programs at the Local Level. US Environmental Protection Agency, Chicago, Illinois, pp. 76-84.

T. Debo, A. Reese Municipal Storm Water Management (second ed.), Lewis Publishers (2002)

J. Delleur The evolution of urban hydrology: past, present, and future J. Hydraul. Eng., 129 (2003), pp. 563573

A. Elliott, S. Trowsdale A review of models for low impact urban stormwater drainage Environ. Modell. Softw., 22 (2007), pp. 394-405

Ellis, J., Green, C., Revitt, D., 2010. Identifying success factors in urban surface BMP implementation: mission impossible? In: GRAIE, Novatech 2010, Lyon, France.

Ellis, J., Revitt, D., Scholes, L., Nascimento, N., Heller, L., Champs, J., 2007. A paradigm switch in urban stormwater management: achieving integrated strategic approaches; the Belo Horizonte example. In: International Symposium on New Directions in Urban Water Management, UNESCO, Paris.

\section{Emerson, C. Welty, R. Traver Watershed-scale evaluation of a system of storm water detention basins}

J. Hydrol. Eng., 10 (2005), p. 237

EPA, 2010. Green Infrastructure Case Studies: Municipal Policies for Managing Stormwater with Green Infrastructure. US Environment Protection Agency. Office of Wetlands, Oceans and Watersheds.

B. Faulkner The control of surface water runoff from new development - UK national 'policy' in need of review? Urban Water, 1 (1999), pp. 207-215

L. Fennessey, J. Hamlett, G. Aron, D. LaSota Changes in runoff due to stormwater management pond regulations J. Hydrol. Eng., 6 (2001), pp. 317-327

G. Freni, G. Mannina, P. GaspareViviani Urban storm-water quality management: centralized versus source control J. Water Resour. Plan. Manage., 136 (2010), p. 268

Fromon, V., Zuindeau, B., 1999. Évaluation de la qualité des cours d'eau. Une approche par la méthode des prix hédonistes appliquée à quatre cas d'étude. Cas pratique II: L’Orge. Technical Report. Université de Lille I Comité Inter-Agences de l'eau.

Gironás, J., Roesner, L., Davis, J., Rossman, L., 2009. Storm Water Management Model Applications Manual. US Environment Protection Agency.

K. Goff, R. Gentry The influence of watershed and development characteristics on the cumulative impacts of stormwater detention ponds Water Resour. Manage., 20 (2006), pp. 829-860 
R. McCuen Downstream effects of stormwater management basins J. Hydraul. Div. ASCE, 105 (1979), pp. $1343-1356$

K.L. Meierdiercks, J.A. Smith, M.L. Baeck, A.J. Miller Heterogeneity of hydrologic response in urban watersheds J. Am. Water Resour. Assoc., 46 (2010), pp. 1221-1237

V.G. Mitchell, R.G. Mein, T.A. McMahon Modelling the urban water cycle Environ. Modell. Softw., 16 (2001), pp. 615-629

P. Morison, R. Brown Understanding the nature of publics and local policy commitment to Water Sensitive Urban Design Landscape Urban Plan., 99 (2011), pp. 83-92

Mouy, N., Duguet, P., Laurent, C., 2007. Faisabilité hydraulique du zonage pluvial à Paris. In: GRAIE, Novatech 2007, Lyon, France.

J. Nash, J. Sutcliffe River flow forecasting through conceptual models part I - a discussion of principles

J. Hydrol., 10 (1970), pp. 282-290

Novotny', V., Brown, P. (Eds.), 2007. Cities of the future: towards integrated sustainable water and landscape management. In: Proceedings of an International Workshop Held July 12-14, 2006 in Wingspread Conference Center, Racine, WI. IWA Publishing, London.

E. O'Connell, J. Ewen, G. O'Donnell, P. Quinn Is there a link between agricultural land-use management and flooding? Hydrol. Earth Syst. Sci., 11 (2007), pp. 96-107

G. Petrucci, J.F. Deroubaix, B. de Gouvello, J.C. Deutsch, P. Bompard, B. Tassin Rainwater harvesting to control stormwater runoff in suburban areas. An experimental case-study Urban Water J., 9 (2012), pp. 4555

Petrucci, G., Tassin, B., 2011. Hydrographs' attenuation in sewers. effects on stormwater source control regulation. In: 12nd International Conference on Urban Drainage, Porto Alegre, Brazil, 11-16 September 2011.

Préfecture de Seine-Saint-Denis, 2008. Dossier départemental des risques majeurs (DDRM).

Quivy, R., Van Campenhoudt, L., 1995. Manuel de recherche en sciences sociales. Dunod, Paris. 2 edition.

Revitt, D., Scholes, L., Ellis, J., 2008. The best management practice catalogue developed within the DayWater project. In: Thevenot, D. (Ed.), DayWater: An Adaptive Decision Support System for Urban Stormwater Management. IWA Publishing, London, UK (Chapter 8).

F. Rodriguez, H. Andrieu, J. Creutin Surface runoff in urban catchments: morphological identification of unit hydrographs from urban databanks J. Hydrol., 283 (2003), pp. 146-168

L. Roesner, B. Bledsoe, R. Brashear Are best-management-practice criteria really environmentally friendly?

J. Water Resour. Plan. Manage., 127 (2001), pp. 150-154

Rossman, L., 2004. Storm Water Management Model (SWMM version 5.0) user's manual. US Environment Protection Agency.

A. Roy, S. Wenger, T. Fletcher, C. Walsh, A. Ladson, W. Shuster, H. Thurston, R. Brown Impediments and solutions to sustainable, watershed-scale urban stormwater management: lessons from Australia and the United States Environ. Manage., 42 (2008), pp. 344-359 
D. Savic, S. Khu Evolutionary computing in hydrological sciences M.G. Andersen (Ed.), Encyclopedia of Hydrological Sciences, vol. 1, John Wiley \& Sons, New York (2005)

V.P. Singh Hydrologic systems Rainfall-runoff modeling, vol. 1, Prentice Hall, Englewood Cliffs, New Jersey (1988)

SIVOA, 2003. Règlement d'assainissement. <www.sivoa.fr/pdf/assainissement.pdf> (visited 07.11).

Urbonas, B., Glidden, M.W., 1983. Potential effectiveness of detention policies. In: Soutwest Storm Drainage Symposium. Texas A\&M, November 1983.

Urbonas, B.R., Jones, J.E., 2001. Summary of emergent urban stormwater themes. In: Urbonas, B.R. (Ed.), Linking Stormwater BMP Designs and Performance to Receiving Water Impact Mitigation, ASCE.

E. Williams, W. Wise Hydrologic impacts of alternative approaches to storm water management and land development JAWRA J. Am. Water Resour. Assoc., 42 (2006), pp. 443-455

Woods-Ballard, B., Kellagher, R., Jefferies, C., Bray, R., Shaffer, P., 2007. The SUDS Manual. CIRIA, London, UK.

J. Wu, S. Yu, R. Zou A water quality-based approach for watershed wide bmp strategies JAWRA J. Am. Water Resour. Assoc., 42 (2006), pp. 1193-1204

C. Zimmer, I. Heathcote, H. Whiteley, H. Schroeter Low-impact-development practices for stormwater: implications for urban hydrology Can. Water Resour. J., 32 (2007), p. 193 